\title{
Evaluating the Impact of Open Access at Berkeley: Results from the 2015 Survey of Berkeley Research Impact Initiative (BRII) Funding Recipients
}

\section{Samantha Teplitzky and Margaret Phillips}

The Berkeley Research Impact Initiative (BRII) was one of the first campus-based open access (OA) funds to be established in North America and one of the most active, distributing more than $\$ 244,000$ to support University of California (UC) Berkeley authors. In April 2015, we conducted a qualitative study of 138 individuals who had received BRII funding to survey their opinions about the benefits and funding of open access. Most respondents believe their articles had a greater impact as open access, expect to tap multiple sources to fund open access fees, and support the UC Open Access Policy and its goal of making research public and accessible. Results of the survey and a discussion of their impact on the BRII program follow.

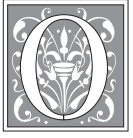

ne of the first campus-based open access funds in North America, the Berkeley Research Impact Initiative was established at UC Berkeley in January 2008 as a pilot program. In the program announcement issued jointly by its cosponsors, the University Librarian and the Vice Chancellor for Research described how this initiative would provide "authors with funds to help cover open access and paid access publishing fees not supported by grants or contracts" and outlined its goal to "maximize the benefits of Berkeley's research for the scholarly community and to advance knowledge." ${ }^{\prime 1}$ The library originally redirected $\$ 60,000$ of collections money to support the BRII program. Within the first years, as the term "pilot" quietly disappeared from documentation and as the collections budget-indeed, the entire library budget - faced cutbacks, the annual BRII budget decreased to $\$ 44,000$.

BRII evolved in other ways as well. By 2014, the program restricted support to only those publishing in "pure open access" journals (that is, the entire journal must be freely available and not charge subscription fees), no longer supporting articles in "hybrid" (subscription-based) journals. Further restrictions included accepting

Samantha Teplitzky is Earth and Physical Sciences Librarian in the Physics-Astronomy Library and Margaret Phillips is Social Sciences Librarian \& BRII Coordinator in the Education/Psychology Library at the University of California, Berkeley; e-mail: steplitz@berkeley.edu, mphillip@library.berkeley.edu. (C) 2016 Samantha Teplitzky and Margaret Phillips, Attribution-NonCommercial (http://creativecommons. org/licenses/by-nc/3.0/) CC BY-NC. 
only one application per author per calendar year. Also, to attract researchers in the humanities and social sciences, BRII funds became available to campus-based publishers using the University of California eScholarship platform to publish OA monographs and journals.

Within the broader landscape, Berkeley collaborated with its UC partners to establish new independently administered campus-based OA funds throughout the system; in early 2013, as a way to encourage all of the UCs to establish funds, UC's California Digital Library (CDL) offered $\$ 10,000$ to interested campuses. Most of the UCs (including Berkeley, which, of course, already had an active program) gratefully accepted the seed money. Also in 2013, the Academic Senate passed the UC Open Access Policy, which ensured that future research articles authored by UC Senate faculty at all 10 campuses would be made available to the public. These two developments, as well as the continued proliferation of OA journals, many of them sponsored by commercial publishers such as the Nature Publishing Group (Scientific Reports) and Elsevier (Cell Reports), underscored the wider acceptance of open access by the academic community. With these changes at the institutional level and in the publishing environment in general, some of the initial goals of the BRII program such as generating "conversations about ... copyright and scholarly communication" no longer seemed as pressing. ${ }^{2}$ Yet the program's original purpose "to foster broad public access to the work of Berkeley scholars by encouraging the Berkeley community to take advantage of open access (OA) publishing opportunities" remains as relevant today as when the program first started. ${ }^{3}$

\section{Literature Review}

There have been few studies of researchers' experiences with campus open access funds and how the use of those funds has influenced their attitudes about open access or their willingness to pay an article processing charge (APC). Most work has focused on quantifying the impact of campus funds, surveying the attitudes of fund managers (not the authors themselves), or analyzing the economics of the author-pays model of funding journals.

The Scholarly Publishing and Academic Resources Coalition (SPARC) defines a Campus Open Access Fund as a "pool of money set aside by an institution to support publication models that enable free, immediate, online distribution of, and access to, scholarly research. ${ }^{\prime 4}$ SPARC first began tracking campus funds more than five years ago with their campus-based open access funds online resource. In that time, the number of funds has grown from 9 to 51. Greg Tananbaum assessed the progress of these funds in SPARC's 2014 "North American Campus-Based Open Access Funds: A Five-Year Progress Report" and found that their success can be measured in part by the more than $\$ 2$ million that have been committed to fund nearly 4,000 research articles. ${ }^{5}$ Campus OA fund managers offered qualitative insights that the funds "underscore an institution's commitment to the principles behind Open Access" and have enabled campuses to support authors who might not have published in open access journals otherwise, but the study did not consider how authors evaluate and interact with the funds. The SPARC study and other resources note the importance of assessing fund progress; but, because most funds are still fairly new, few such studies have been executed for individual funds. ${ }^{6}$

Monson et al. surveyed 10 academic institutions whose libraries were involved in the creation or administration of an open access fund. ${ }^{7}$ Although they did not survey faculty directly, librarians at these institutions felt that the funds increased their ability to discuss OA with faculty, reporting that faculty provided positive feedback for the funds, and perceived an increased impact and reach of their research. Nariani and Fernandez surveyed a small pool of researchers at York University whose author-processing 
charges had been subsidized by institutional memberships in BioMed Central, Public Library of Science (PLoS), and Hindawi. ${ }^{8}$ Their qualitative study showed that author funding can provide an incentive for researchers to publish in OA journals, but their cohort and selection of journals was limited.

In an economic analysis of APC-funded journals, Solomon and Björk analyzed some 1,825 journals, concluding that APC rates charged by journals are market-driven and influenced by the perceived prestige of the journal and the levels of funding available for the disciplines in which it publishes (thus explaining why APC-based OA publishing is concentrated in STEM fields). And, while the authors identified research grants and institutional funding as the dominant modes of financing APCs, they did not examine researcher attitudes or beliefs about how best to fund APCs. ${ }^{9}$ Subsequent studies by Björk and Solomon explored the market for APC-funded OA journals; although they did survey authors about their funding sources, the study did not gauge author attitudes about APC funding models or the perceived benefits of OA publishing. ${ }^{10}$ Peterson et al. analyzed the imbalance of the author-pays model of financing open access publishing, arguing that "the 'author-pays' model poses a significant problem by creating a system in which access becomes more open to readers but simultaneously more closed to authors."11 While a program like BRII and a similar one at their home institution seeks to address those inequities by funding authors who do not otherwise have access to grant funding to pay APCs, Peterson et al. did not analyze authors' attitudes about this funding model; rather, they called for broader OA experimentation as a way of increasing access to scholarship for authors globally. Our survey enabled us to hear from authors directly, both about their experiences with a campus fund and their opinions about open access publishing fees.

\section{Methods}

Because of the $\$ 10,000$ seed money granted to each campus by the California Digital Library (CDL) in 2013 to establish OA funds, the Collections Licensing Subcommittee (CLS), a representative group of UC librarians who advise CDL on UC systemwide digital collections, charged a task group to develop a set of survey questions as part of its continuing assessment effort. The Open Access Fund Assessment Questions Task Group developed a set of common questions that campuses could use, if they chose, to gather information about their OA funds. ${ }^{12}$ The idea was that, by using the same questions, comparisons could be made more easily across the campuses. In April 2015, UC Berkeley administered a survey based on the questions developed by this group. It should be noted, however, that there was significant variation across the campuses in practices for administering their OA funds. Reimbursement limits ranged from $\$ 1000$ to \$3000; some campuses reimbursed for articles published in hybrid journals, and others did not; and some campuses did not fund authors who already had grant funding. ${ }^{13}$

In our survey design, we began by identifying the survey audience. Establishing data (and thus determining who to survey) about the BRII program was challenging because the guidelines and criteria for funding evolved over the years. To conduct our study, we compiled statistics based on our current BRII criteria. ${ }^{14}$ We only surveyed BRII-funded authors who published in pure OA journals, despite the fact that, until early 2014, BRII supported articles in hybrid journals. We also restricted our data gathering by tracking no more than four articles by those authors who had received BRII funds on multiple occasions. However, current criteria limit individuals to one application per calendar year. Based on these restrictions, we determined that, from the beginning of the program in 2008 through the spring of 2015, BRII funded 177 articles by 138 individuals and distributed more than $\$ 244,000$. According to data gathered by SPARC, this makes the BRII program one of the most active campus-based OA funds in the North America. ${ }^{15}$ 
We did further breakdowns to provide a more detailed picture of whom BRII has supported by discipline and status. We classified our authors by broad subjects as defined by major administrative units on campus. Natural Resources, for instance, which accounts for the largest number of authors who have received BRII support, comprises departments in Berkeley's College of Natural Resources, including the departments of Environmental Science, Policy \& Management (ESPM), Plant \& Microbial Biology, and Agricultural \& Resource Economics.

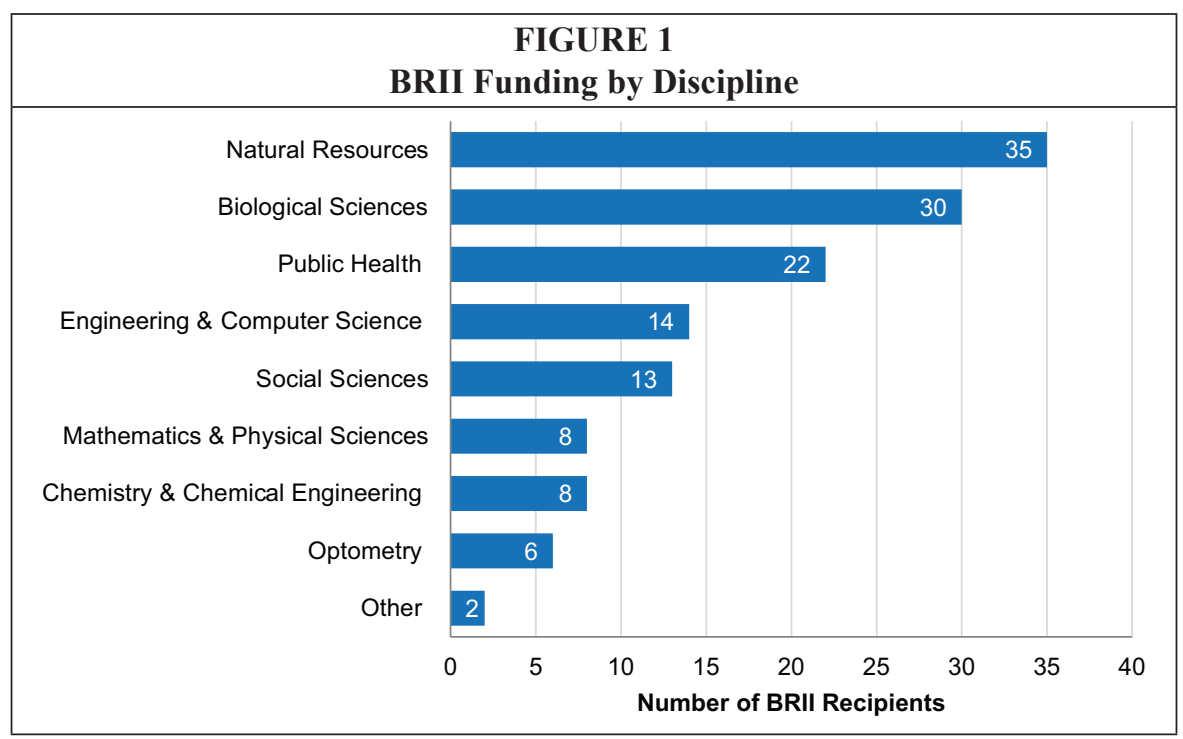

We also analyzed the academic status of the BRII applicants surveyed. Tenure-track faculty members represented the largest percentage of those receiving BRII funds $(49 \%)$, but postdocs $(18 \%)$, graduate students $(22 \%)$, and other researchers $(11 \%)$ also availed themselves of BRII money.

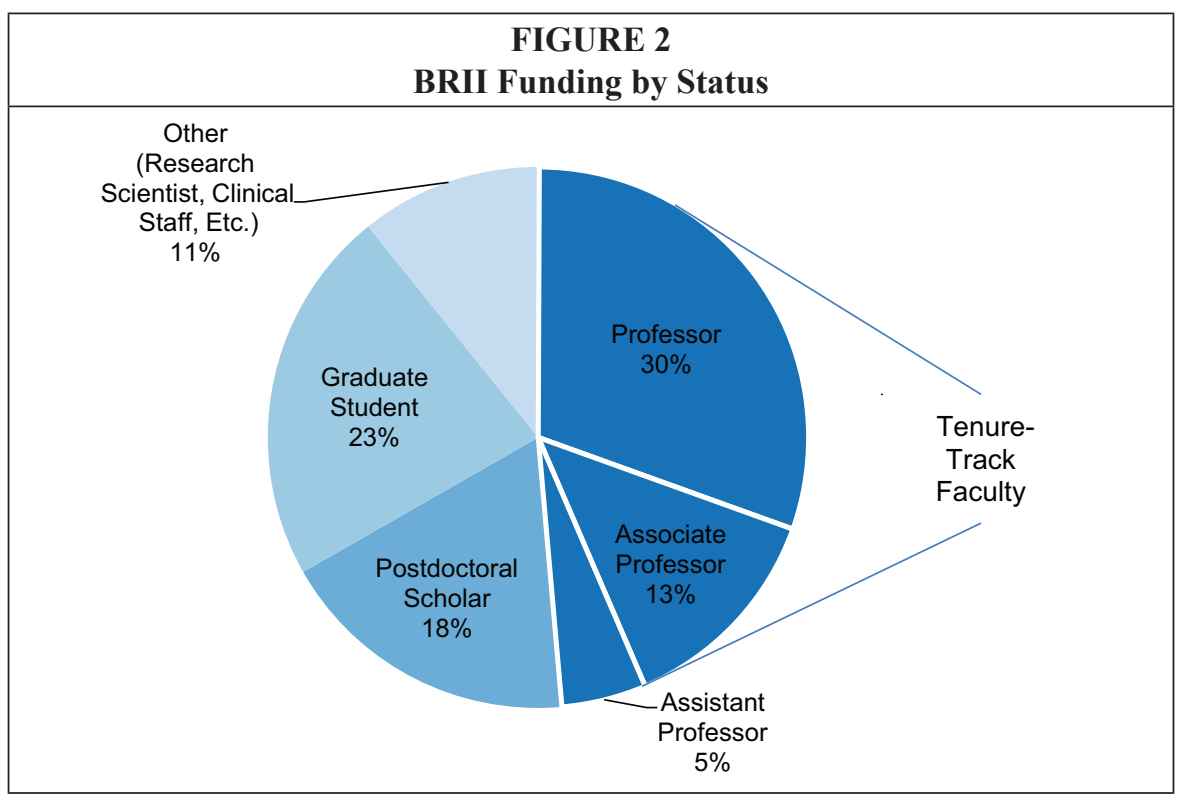


Of the recipients, 115 had one article funded and 23 had multiple articles funded. We used the UC Berkeley licensed Qualtrics Survey platform to perform the survey and contacted respondents using the information they had shared with their original funding applications. Using the Qualtrics Mailer, we then created customized e-mail invitations, including a personalized greeting and a citation to the article(s) funded by BRII. Survey invitations were e-mailed on April 14, 2015; a first reminder was sent on April 23, 2015, followed by a final reminder on April 30, 2015; and the survey closed on May 1, 2015. The survey took an average of 6 minutes to complete. Survey responses were anonymous, and the Committee for Protection of Human Subjects at Berkeley approved our study protocol and survey.

There were inevitable limits to our survey, including the fact that, due to the changing eligibility guidelines for BRII funding, we did not actually survey all those who had received funding. The academic status of those surveyed may have changed between the time they applied for funding and the time we surveyed them (junior faculty, for instance, may have been granted tenure). Although BRII has attempted to attract more scholars in the humanities and social sciences by opening up funding for OA monographs and journal publishers, the vast majority of those who responded to the survey are in STEM fields; thus, our findings do not fully represent the attitudes of the campus academic population. Finally, the fact that we surveyed authors who have published OA and are likely to have a positive attitude toward open access may also not accurately represent the campus population.

A copy of the survey is included as an appendix. Survey questions addressed three aspects of open access: attitudes, beliefs, and habits; perceived impact of publishing open access; and opinions about funding for open access publications. We also solicited feedback about the UC Open Access Policy. We used the Qualtrics reporting feature to evaluate our multiple choice questions; but, because the graphing function did not give us enough flexibility to present our data visually, we downloaded the data into Google Sheets and Excel to create charts. For those queries in which we solicited free-text responses, we coded specific key terms looking for patterns and trends. We then identified major themes and subthemes in those responses, grouped the themes together and selected unique, sometimes contradictory, but always insightful quotes to highlight in our results.

\section{Results}

Our survey response rate was 72 percent: 99 out of 138 of our pool completed the survey, and all respondents who opened the survey e-mail went on to complete the survey. Responses were anonymous and could not be linked to individuals, but Qualtrics did allow us to see who had completed the survey. Based on that list of e-mails, we could estimate that the profile of our respondents roughly matched the profile of BRII recipients. Mathematics \& Physical Sciences were slightly underrepresented (4\% of respondents vs. $6 \%$ of recipients), but the proportion of respondents from the other disciplines shown in figure 1 were all within 1 percent (for example, Public Health represented $17 \%$ of the respondents and $16 \%$ of the recipients).

We report qualitative themes identified in respondents' comments below.

\section{Open Access: Attitudes, Beliefs, and Habits}

Having received funding from BRII to publish open access, it was not surprising that our pool of respondents was supportive of open access publishing. Eighty-nine percent agreed that the availability of BRII to help pay the APC or open access fee for the cited article affected their decision about where to publish, and 44 percent had not published an open access article prior to the one funded by BRII. At the same time, if 
they had not received funds from BRII, 34 percent would have published the article as subscription access, 39 percent were not sure, and 22 percent would have looked for another funding source. Respondents explained that, without BRII funding, they would have "published in a less prestigious journal," "gotten co-authors to pay for it," or "used money from my federal funds." Many respondents are not necessarily open access advocates but were willing to try open access when BRII funds provided an opportunity to defray publication costs.

\section{Open Access: Greater Perceived Impact}

Most respondents (82\%) believed that their article had a greater overall impact because it was open access. Figure 3 shows the benefits that respondents believe their BRIIfunded open access article accrued compared to other articles they had published in subscription-based journals. Most respondents listed a greater number of views and more downloads as the primary benefits. Many articles are too new to have demonstrated an increased number of citations, but that was still the third most highly ranked benefit of publishing open access.

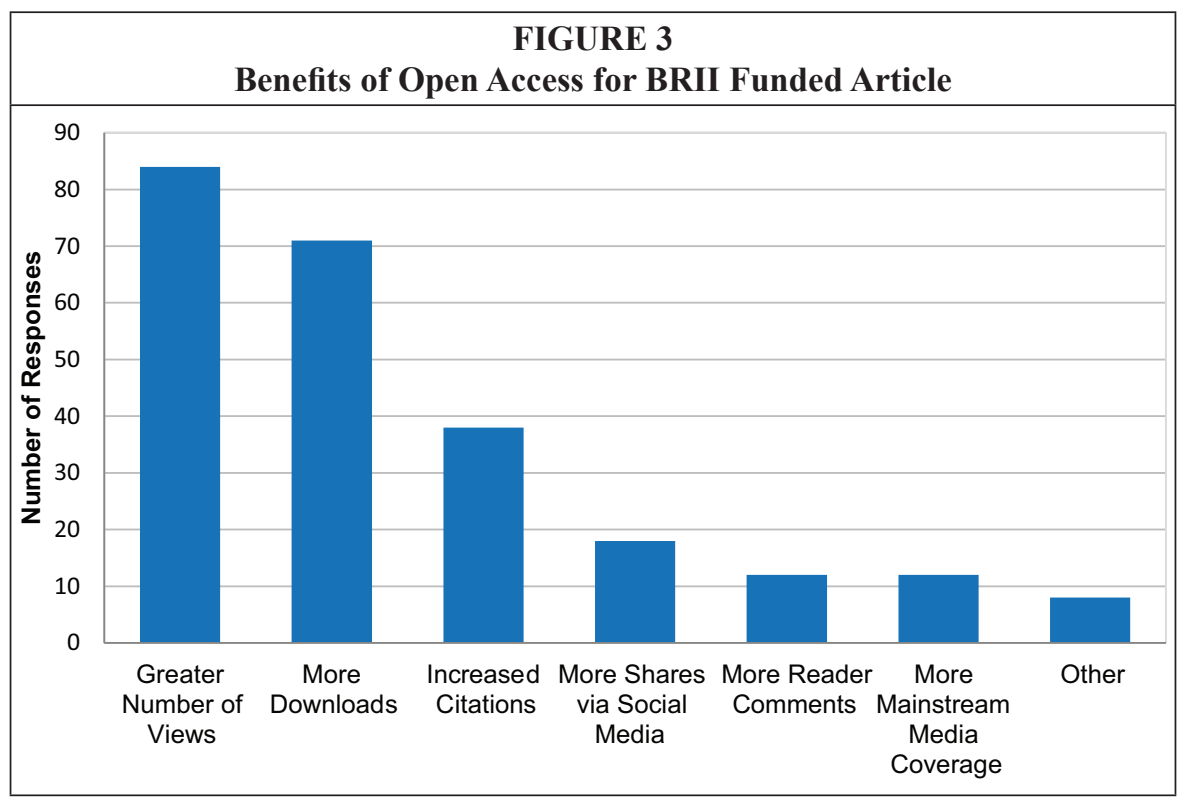

Respondents provided additional insights on the perceived benefits of open access. One researcher received "invitations by the same journal to submit more articles," while another noted:

"The press office wrote a release, and we got a front page story in the SF Chronicle on day of publication. A Gordon and Betty Moore Fdn program officer read the article, and reached out to me. That contact has since resulted in almost $\$ 2 \mathrm{M}$ in funding, and had a major impact on the direction of my research. I think Open Access makes a difference in reporter's interest in covering stories, though I can't prove it!" 


\section{Funding: Larger Role for the University}

Respondents' answers to the multiple choice question "How have you previously covered Article Processing Charges for open access publications?" are shown in dark blue in figure 4. Respondents had previously covered APCs for open access publications with departmental funds, grant funds, personal funds, and coauthor funds. A small number (included in "other") had asked for waivers from publishers or had received BRII funding in the past.

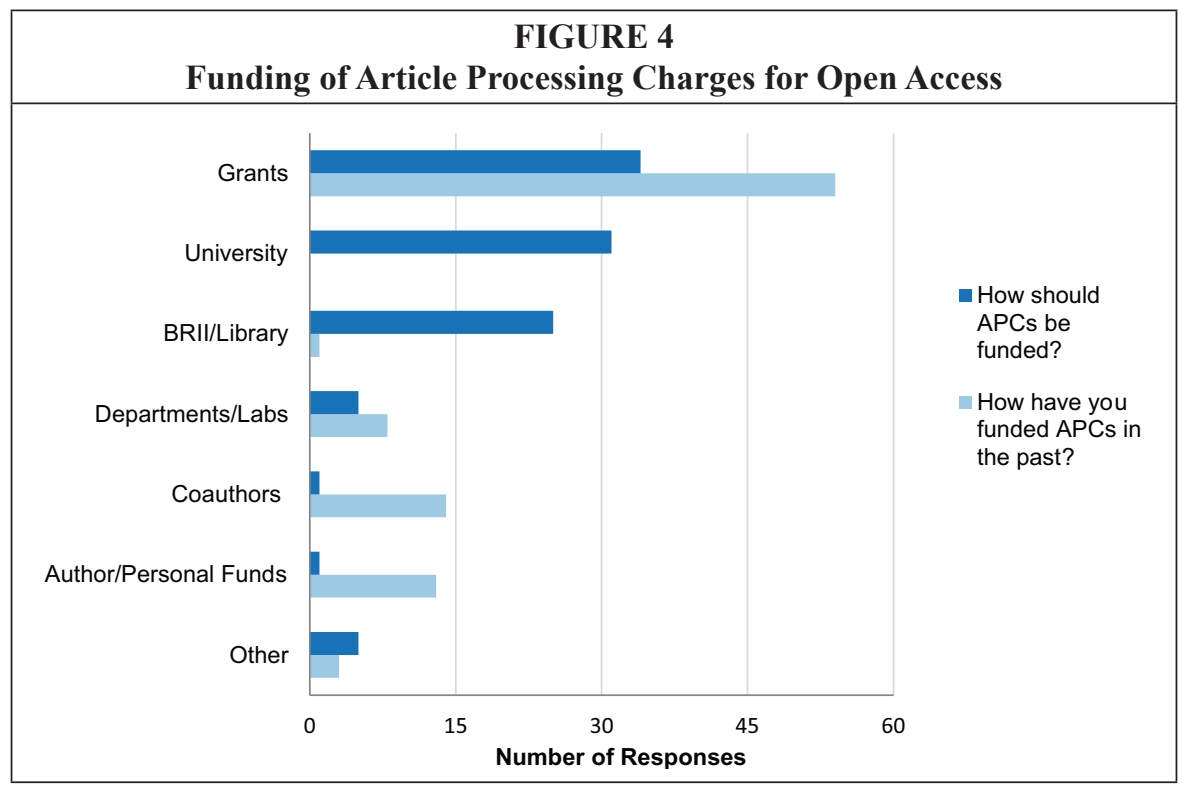

When asked to write in suggestions regarding how open access publishing costs should be covered, opinions varied. We qualitatively coded responses to fit into the prior categories that detailed how respondents had previously funded APCs. (These responses are shown in light blue in figure 4.) Half of our respondents recommended accessing multiple sources, including some combination of grants, university funding, or BRII funding. They mentioned other sources of funding such as personal or author funds in smaller numbers. Notably, respondents may have used personal or coauthor funds in the past (27 respondents) but do not believe this is a sustainable model for the future (2 respondents).

Grants were listed as potential sources most often (31 times), but respondents also noted that grants are shrinking, and often articles are published after an official grant project has closed:

"BRII has provided a helpful (and truly invaluable) backstop in these situationsthere have been many cases where we would have been forced to publish behind a paywall without BRII support."

"If grant funding is available then open access charges should come from the grant. But when the grant is finished and there are no alternate funds there needs to be some other sources to pay the APC. Also some excellent projects from undergraduate researchers are not funded by a grant but results in publishable research..." 
Respondents felt just as strongly that the university (referred to also as "campus" or "the institution") should take a larger role in funding open access publications (28 mentions). One stated, "If the university wants professors to publish open access, it needs to provide resources for professors to do so." Another suggested that the university might offer funding "through a competitive process, preferencing early career scientists, people without other funding, and potentially high-impact work."

Finally, BRII (or the library) was recommended 22 times as a means of covering open access costs. Many were supportive of BRII in its current form, with one respondent noting "as a grant-funded employee, this service, as it exists is nearly perfect for me." Another commented, "I really like the BRII model. As citations and articles are critical to Berkeley's reputation, the University should support such efforts when grant funding is not enough."

Although the goal of our survey was not to evaluate BRII, many respondents provided positive comments about the program ("Thank you BRII," "Really appreciate BRII.") while others provided suggestions on how to better administer the program. Specifically, some expressed a desire for the BRII program to pay publishers directly, and others critiqued the current BRII policy that requires an article to have been accepted before the application for funding is considered. One respondent expressed frustration with these circumstances:

"the combination of stating that BRII will stop funding APC when the funds run out and being able to apply for BRII only after acceptance discourages authors from OA who have limited funds because they do not know if they will be left with a debt of thousands of dollars that will have to be paid from personal funds."

There was some criticism related to how much money is available, as BRII funding often runs out before the fiscal year ends. Some respondents proposed constructive solutions to BRII's funding limitations, such as soliciting contributions from VCRO (Office of the Vice Chancellor for Research) or "perhaps splitting the cost will allow the program funds to remain stronger while still supporting open access publishing." Respondents also felt that BRII should be expanded to "demonstrate UC Berkeley's commitment to OA."

\section{Immediate Open Access Preferred Despite New OA Policy}

For more than a decade, authors at UC Berkeley have had the option to take advantage

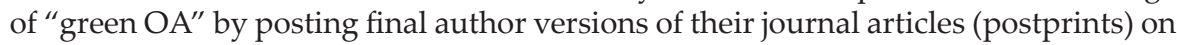
the eScholarship platform; also, many funding agencies, most notably the National Institutes of Health $(\mathrm{NIH})$, require authors to make a final author version of their articles available via agency-sponsored repositories such as PubMed Central. The 2013 Academic Senate passage of the UC Open Access Policy, however, formalized this practice for faculty at all 10 UC campuses, creating centralized tools to ease faculty participation. The policy was rolled out by three UC campuses (Irvine, UCLA, and UCSF) starting in November 2013, with the rest of the campuses following suit in November $2014 .{ }^{16}$ Within the first year of the program, participation, which involved a voluntary manual submission process, was low. Understanding that the manual submission process would be onerous for most faculty authors, the Office of Scholarly Communication, the unit charged with administering the policy for UC, investigated and ultimately licensed an automated system (UC Publications Management system) to harvest publication metadata and assist in uploading faculty postprints to eScholarship. At the three early adoption campuses, faculty participation increased dramatically after the implementation of the publication management system. ${ }^{17}$ 
Anticipating a similar pattern, UC Berkeley has delayed its outreach efforts about the policy, waiting for the harvesting tool to be put in place. Not surprisingly, as of this writing few faculty are even aware of the policy, let alone actively participating in it. When asked how these policies would impact their decision to publish in an OA journal that requires an APC, 77 percent of those surveyed said they would still pay an article process charge to publish in an OA journal so that the final version of their article would be immediately available to the public. Only 12 percent no longer feel the need to publish in an OA journal because of the UC Open Access Policy and/or other funding agency policies.

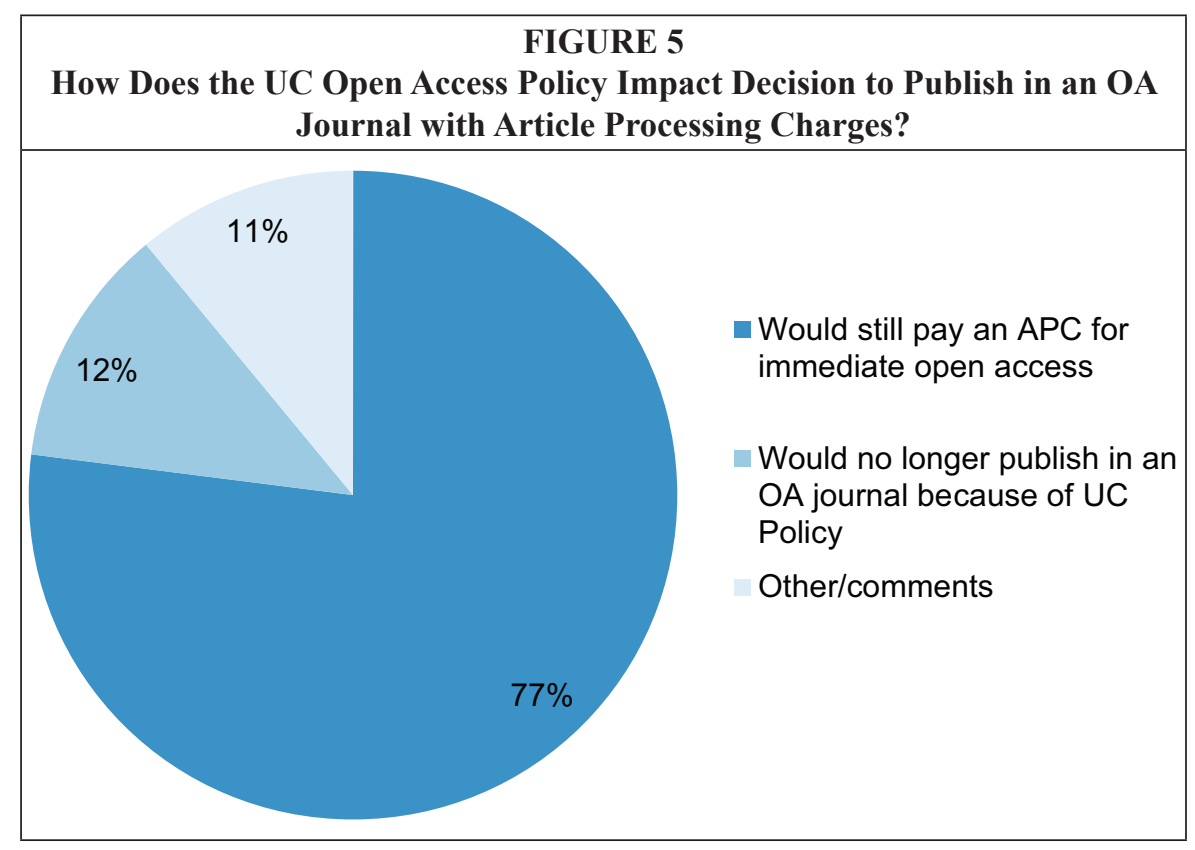

Many respondents were supportive of the UC Open Access policy but stated that it would not influence where they publish. Others feel that prestige takes precedence over access. For example, one researcher commented, "For any given article, I would feel the need to ensure that it appears in a journal known for its high quality and rigorous review process." Others were still unaware of the policy but glad to learn of it: "I wasn't aware of the details of the UC Open Access Policy. I will take advantage of it for articles not in open access publications."

Many support "gold OA" (that is, immediate public access at time of publication) over an institutional repository for the ease of sharing papers:

"When people hit a paywall, unless they know that the article is really critical to their work, they won't go to the trouble to track down a paper. They could always have contacted the author, but often don't. Open Access takes away this friction."

“...open access journals are still preferred to me over posting my paper on my own website (or a repository such as the one at UCB) because it removes one step in the process for other scientists trying to get a hold of some paper of mine they discovered on Pubmed." 
However, disciplinary differences influenced respondents' perception of the policy. In disciplines with a history of preprint sharing, the idea of posting to a repository is already accepted: "I already felt this way, since mathematics articles are freely available on the arXiv." In contrast, another commenter asserted "no one wants to read final manuscript versions, so I don't see this as a substitute."

\section{Discussion}

When we administered our survey during two weeks in April 2015, we were amazed not only by the survey's 72 percent response rate, but also by the respondents' thorough and thoughtful comments. Many overarching themes emerged from these comments: BRII provided a motivation and an opportunity to try open access; multiple funding streams are supported to pay APCs with the expectation the university should play a larger role; publicly funded research should be made public and accessible; and there is some frustration with the current scholarly publishing landscape.

\section{Opportunistic Open Access}

Our respondents are all researchers who have applied for and been granted funding to publish open access through BRII. While it is not unexpected that they support open access and believe that open access benefits their work, many of our respondents are not necessarily OA converts; they are, however, willing to try open access in exchange for BRII funds.

"Like most researchers I select the best journal to publish my research in. If the top choices are an OA journal and a subscription journal and there are funds to pay the APC then I select the OA journal. If there are no funds for the APC and the publishing costs in the subscription journal are significantly less th[e]n I have to choose the subscription journal. BRII allows me to not eliminate OA journals as an option for research that does not have funding to pay the APC."

One researcher noted that BRII is an effective tool for changing the minds of faculty who are entrenched in more traditional publishing models. It would have been interesting to evaluate such statements by tracking potential correlations between career status and opinions about open access. But because our survey was anonymous and our pool somewhat small, we did not ask or record the academic status of respondents. Although we know the percentages of those surveyed according to category, we can draw no conclusions regarding OA attitudes according to career status. We did ask respondents how many articles they had published open access prior to the one funded by BRII $(0,1-5,6+)$, and tried to use this question as a proxy for status, assuming graduate students, postdocs, and early-career professors were likely to have published none or fewer OA articles. We compared answers to the question "in your opinion, how should open access publishing costs be covered?" according to OA publishing history and found no discernible difference among groups. Regardless of how many articles they have previously published OA, respondents agreed that multiple funding sources are necessary, with grants, university funding, and BRII each mentioned about one third of the time.

\section{Support for Multiple Funding Sources, but Larger Role for University}

As seen above in figure 4, respondents support the use of multiple funding sources to pay APCs, but they feel that the university should offer greater contributions. That concern was expressed with two variations. First, respondents felt that the university should do more for researchers with less funding, those between funding, and students 
without grants. One researcher explained, “...many people in my field (even here at Berkeley) are less well funded than I and this is a great resource to help them." Although our population was largely scientists, they expressed support for those scholars who draw from smaller funding streams. As one respondent wrote, "...professors in other fields (such as humanities and social sciences) do not always have access to large grants that fund these high costs of open access publishing."

Second, respondents felt that the university should offer monetary support for its open access policy. These respondents may not understand that the OA policy does not require author payments, but the sentiment seems to acknowledge the benefit of the university's commitment to making its research findings more publicly available.

\section{Making Research Public and Accessible}

While there was some misinformation expressed about the relatively new UC Open Access Policy, those who knew about it were supportive of its goals. When Berkeley begins using the publications management software already implemented by the other campuses, we hope that much of the confusion will be resolved. Respondents support the mission of our public university and believe that the publications resulting from their research should be made public, commenting, "It is very important that a public university publishes its research in a way that is accessible to the PUBLIC..." Their support of open access and their use of BRII predates the University of California's policy; therefore, it is not surprising that most respondents report that they will continue paying APCs in spite of the policy. Some noted that, in the past, uploading articles to eScholarship was too difficult and that author versions were not sufficient. It will be interesting to observe whether these attitudes change after Berkeley implements our publication management system.

\section{Scholarly Publishing in Flux}

Many respondents' ambivalence about the evolution of open access and the rates of APCs reflected a frustration with the current model of scholarly publishing in general, both in terms of their own ability to pay and the impact on library budgets. One researcher commented that "journals have shifted their business model from charging libraries exorbitant funds for subscriptions to charging authors exorbitant fees for OA and then having the authors get funds from grants or their institutions." Another stated, "In my opinion, open access publishing costs should simply be reduced. Preparing publication-quality manuscripts is so easy now. I feel that the operation should really be a lot less expensive."

From the beginning, acknowledging scholars' freedom to choose where to publish BRII-funded articles was a core principle of the program. Indeed, the most important factor that authors consider when selecting where to publish is the prestige and quality of the journal; this factor is, understandably, more important than supporting alternate models of scholarly publishing (if OA is to be considered an alternate model). "The primary reason I choose journals is not for open access but for the quality/prestige of the journal. Open access is then a powerful additional benefit," wrote one respondent. By participating in BRII, Berkeley authors seem to have successfully bridged the idea of supporting new models for scholarly communication with high-quality publications. As one respondent wrote, "Yes there are low cost options for OA but many researchers are concerned that publishing in them will be to the detriment of their promotion and career. BRII allows researchers ... to publish in highly regarded open access journals." Our data about where BRII-funded authors publish indicate that more than 50 percent published in PLoS or BioMed Central, established, reputable publishers of high-quality research. 


\section{Conclusion and Future Directions}

Our study has drawn many significant conclusions. Recipients of open access funding from the Berkeley Research Impact Initiative believe that their articles received more attention and had a greater impact that they might have had in a subscription journal. There was a perception by the respondents that their articles were viewed more, downloaded more, and, to some extent, cited more. They are willing to draw from multiple sources to fund open access fees. Grants and campus funds like BRII are considered two important sources, and they also feel that the university should do more to defray costs and support researchers with less funding. Berkeley researchers are concerned about the future of scholarly publishing and knowledgeable about how to maximize the reach of their work within the present system. BRII remains a valued resource for these authors and fills a vital role as a funding source for open access publications.

This is our first in-depth analysis of BRII recipients; we hope to continue our study. In the future, we intend to compare our responses with other UC campuses if and when they use the task group's survey questions. We believe that our study would translate to other institutions beyond the University of California as well. We will also consider extending our qualitative study of scholars' attitudes about OA by surveying members of the campus community who did not receive BRII funding. As the open access landscape continues to evolve, we hope to examine the emerging advantages, if any, of publishing in OA "mega journals" like PLOS ONE and Scientific Reports, which provide limited peer review but allow for rapid dissemination of research results. And, as we begin our outreach for the UC Open Access Policy publication management software, we will monitor changing attitudes toward the policy and use of the eScholarship platform. We will continue to track new trends and models in scholarly communication and adapt BRII accordingly.

\section{Appendix: Berkeley Open Access Survey}

Q1. Did the availability of the Berkeley Research Impact Initiative (BRII) to help pay the Article Processing Charge (APC) or open access fee for this article affect your decision about where to publish?
$\square$ Yes
$\square \quad$ No
$\square \quad$ Not sure

Q2. If you had not received funds from BRII to publish your article open access, would you have:

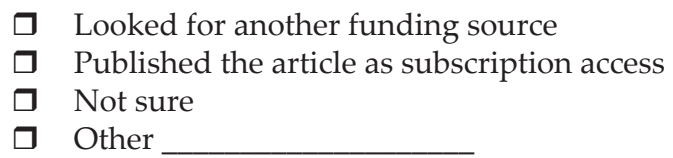

Q3. How many open access articles had you published prior to the one you received funds for?
$\square \quad 0$
ㅁ $1-5$
$\square \quad 6$ or more
$\square$ Not sure 
Q4. Do you believe that your article had a greater overall impact because it was open access?
$\square \quad$ Yes
$\square \quad$ No
$\square \quad$ Not sure

Q5. Compared to articles you have published in subscription-based journals, do you believe your open access article benefited from any of the following? (check all that apply)
$\square \quad$ Increased citations
$\square$ Greater number of views
$\square$ More downloads
$\square$ More shares via social media (Twitter, Facebook, and the like)
$\square$ More reader comments
$\square$ More mainstream media coverage
$\square$ Other

Q6. How have you previously covered Article Processing Charges (APCs) for open access publications? (check all that apply)

$\square$ Departmental funds

$\square$ Grant funds

ㄱ Personal funds

$\square \quad$ APC paid by coauthor(s)

$\square$ Other (please specify)

$\square$ Not applicable

Q7. In your opinion, how should open access publishing costs be covered?

Q8. Authors at UC Berkeley have other options for making their research findings freely available online with no additional charges. With the UC Open Access Policy, faculty can post the final author's version of their scholarly articles on eScholarship; also many funding agencies require authors to make a final author's version of their articles available via their repository (such as PubMed Central). Please indicate how (if at all) these policies impact your decision to publish in an open access journal that requires an article process charge:

$\square \quad$ I would have still paid an article processing charge to publish it in an open access journal so that the final version of my article is immediately available as open access.

$\square \quad$ I no longer feel the need to publish in an open access journal because of the UC Open Access Policy and/or funding agency open access policies.

$\square$ Comments:

Q9. Are there other comments you wish to share about the BRII or open access in general?

\section{Notes}

1. Thomas C. Leonard and Beth Burnside, “New Program Announcement: Berkeley Research Impact Initiative" (Jan. 21, 2008), available online at http://guides.lib.berkeley.edu/ld.php?content_ id=11364690 [accessed 27 May 2015].

2. Charles D. Eckman and Beth T. Weil, "Institutional Open Access Funds: Now Is the Time," 
PLoS Biology 8, no. 5 (May 25, 2010): e1000375, doi:10.1371/journal.pbio.1000375.

3. UC Berkeley Library, "Berkeley Research Impact Initiative (BRII): Program Description," available online at http://guides.lib.berkeley.edu/brii [accessed 27 May 2015].

4. SPARC: Scholarly Publishing and Academic Resources Coalition, "Campus-Based OpenAccess Publishing Funds," available online at www.sparc.arl.org/resources/funds [accessed 27 May 2015].

5. Greg Tananbaum, "North American Campus-Based Open Access Funds: A Five-Year Progress Report" (Washington, D.C.: SPARC: Scholarly Publishing and Academic Resources Coalition, Fall 2014), available online at www.sparc.arl.org/sites/default/files/OA\%20Fund\%20 5\%20Year\%20Review.pdf [accessed 27 May 2015].

6. SPARC: Scholarly Publishing and Academic Resources Coalition, "Reporting the Fund's Progress," available online at www.sparc.arl.org/resources/funds/progress [accessed 27 May 2015].

7. Jane Monson, Wendy Highby, and Bette Rathe, "Library Involvement in Faculty Publication Funds," College \& Undergraduate Libraries 21, no. 3/4 (July 3, 2014): 308-29, doi:10.1080/1069 1316.2014.933088.

8. Rajiv Nariani and Leila Fernandez, "Open Access Publishing: What Authors Want," College E Research Libraries 73, no. 2 (Mar. 1, 2012): 182-95, doi:10.5860/crl-203.

9. David J. Solomon and Bo-Christer Björk, "A Study of Open Access Journals Using Article Processing Charges," Journal of the American Society for Information Science and Technology 63, no. 8 (Aug. 1, 2012): 1485-95. doi:10.1002/asi.22673.

10. Bo-Christer Björk and David Solomon, "Developing an Effective Market for Open Access Article Processing Charges" (London, U.K.: Wellcome Trust, March 2014), available online at https://wellcome.ac.uk/sites/default/files/developing-effective-market-for-open-access-articleprocessing-charges-mar14.pdf [accessed 22 July 2015].

11. A.T. Peterson, Ada Emmett, and Marc L. Greenberg, "Open Access and the Author-Pays Problem: Assuring Access for Readers and Authors in a Global Community of Scholars," Journal of Librarianship and Scholarly Communication 1, no. 3 (Feb. 28, 2013). doi:http://dx.doi.org/10.7710/21623309.1064 .

12. Members of the task group included: Roxanne Peck, UCLA; Margaret Phillips, Berkeley (chair); Anneliese Taylor, UCSF; Samantha Teplitzky, Berkeley; Mary Wood, Davis. Julia Kochi, UCSF, served as CLS liaison.

13. J. Wilson, D. Setzer, and M. Wood, UC Libraries Open Access Publishing Fund Pilot: An Assessment Report to SAG 1 and CLS, California Digital Library (CDL) (2014), 15, available online at http://libraries.universityofcalifornia.edu/groups/files/cls/docs/UC\%20Open $\% 20$ Access $\% 20$ Pilot\%20Report\%20FINAL\%20072914.pdf [accessed 27 May 2015].

14. More details about current BRII criteria can be found here: http://guides.lib.berkeley.edu/ brii/guidelines [accessed 27 May 2015].

15. "Open Access Funds in Action" (Washington, D.C.: SPARC: Scholarly Publishing and Academic Resources Coalition, October 1, 2014), available online at www.sparc.arl.org/sites/ default/files/OA \%20Funds\%20in\%20Action\%20attachment $\% 202014 \% 20 \% 281 \% 29$.pdf [accessed 27 May 2015].

16. Mitchell C. Brown, Bethany R. Harris, and Julia M. Gelfand, “UC Open Access Policy: Not Always the Field of Dreams, but the Field of Hope," eScholarship (Apr. 29, 2015), available online at http://escholarship.org/uc/item/1gn2p4xt [accessed 27 May 2015].

17. Katie Fortney, "UC Launches Robust Publication Management System in Support of Open Access Policy Office of Scholarly Communication," available online at http://osc.universityofcalifornia.edu/2015/04/uc-launches-robust-publication-management-system/ [accessed 6 June 2015]. 